\title{
Study on Processing Parameters of Cold Spray Al coating on Magnesium Alloy
}

\author{
LIU Yuliang ${ }^{1,2}$ a, ZHANG Qing ${ }^{1,2}$ \\ ${ }^{1}$ School of Materials Science and Engineering, Henan University of Science and Technology, \\ Luoyang, China \\ ${ }^{2}$ Collaborative Innovation Center of Nonferrous Metals, Henan Province, Luoyang, China \\ apurelandliu@126.com
}

Keywords: processing parameters, Cold spraying, orthogonal design, coating density

\begin{abstract}
Cold spray in used to form Al coating on AZ31 magnesium alloy. Several parameters, such as spraying distance, gas temperature, and gas pressure are selected as the main processing parameters for cold spray. According to orthogonal design, orthogonal experiments are designed for the optimization of processing parameters. coating density is employed to test processing result. Optimized Al coating on AZ31 magnesium alloy are sprayed by spraying distance $30 \mathrm{~mm}$ under pressure of 2.1 MPa at $310 \mathrm{C}$.
\end{abstract}

\section{Introduction}

As the lightest metal structural material, magnesium alloys show promise in aerospace, electronics and automotive industries for their excellent physical and mechanical properties, such as the low density, high strength-to-weight ratio, high stiffness and mechanical castability [1-3] However, because of the low wear resistance and high chemical reactivity of Mg alloys, surface treatment is normally required for $\mathrm{Mg}$ alloy components in order to improve their surface durability. Different surface treatment techniques have been developed and used to improve the corrosion resistance of magnesium alloy, such as micro-arc oxidation [4], chemical conversion [5], plating [6] and chemical vapour deposition [7]. However, due to the high chemical activity of magnesium in aqueous solutions, most of the existing surface treatment techniques fail to offer sufficient protection for magnesium alloy components in their service environments.

The emerging cold spray ( CS ) coating process has potential for use as a simple technique for surface protection of magnesium alloys. In the cold spray process, micro-particles are accelerated to supersonic velocities and impact onto a substrate surface ${ }_{2}$ the coating is formed by plastic deformation of sprayed particles in a solid state during impact in cold spraying. The temperature of spray particles prior to impact is much lower than their melting point and spray materials experience little microstructure change, oxidation or decomposition [8]. Most metals including $\mathrm{Cu}, \mathrm{Al}$ and their alloys can be deposited by cold spraying [8-9], and even cermets [8]or ceramic particles [9]can be embedded into a metal substrate to form a thin layer coating. The bonding of particles in cold gas spraying is presumed to be the result of extensive plastic deformation and related phenomena at the interface. The bonding mechanisms in cold gas spraying can thus be compared to those in processes such as explosive cladding or shock wave powder compaction. These latter processes have been explored widely with respect to mechanisms of bonding as well as to possible applications [10].

This paper is to study and improve the main processing parameters of cold spraying Al coating on AZ31 magnesium alloy.

\section{Experiment and results}

Commercially pure aluminum powder produced by gas atomization was used as feedstock material. The particle size and shape were examined by scanning electron microscopy (SEM, JSM-5610LV). As shown in Fig. 1, the diameters of the spherical Al particles range from 1 to $40 \mu \mathrm{m}$. As-cast AZ31D 
magnesium alloy was used as substrate for cold spraying. The substrate was ground with abrasive papers up to 800 grit, cleaned with acetone, and then sandblasted using 24 mesh alumina grits prior to cold spraying. Fig 2 shows the schematic drawing of CS system.

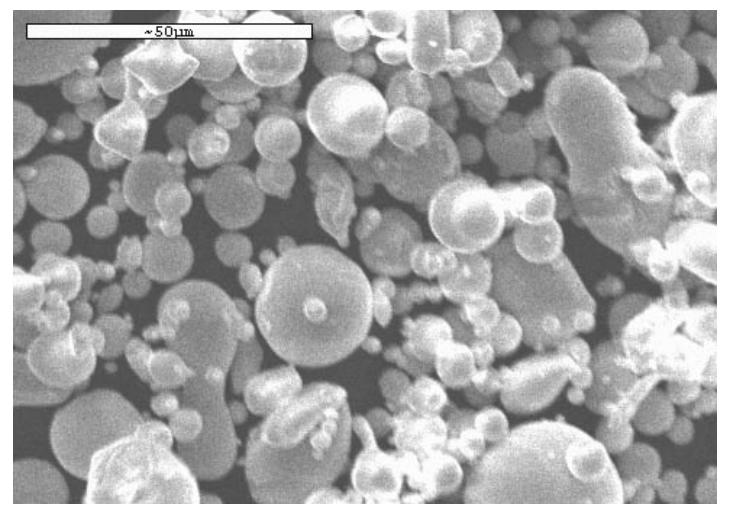

Fig 1 SEM image of aluminum powders

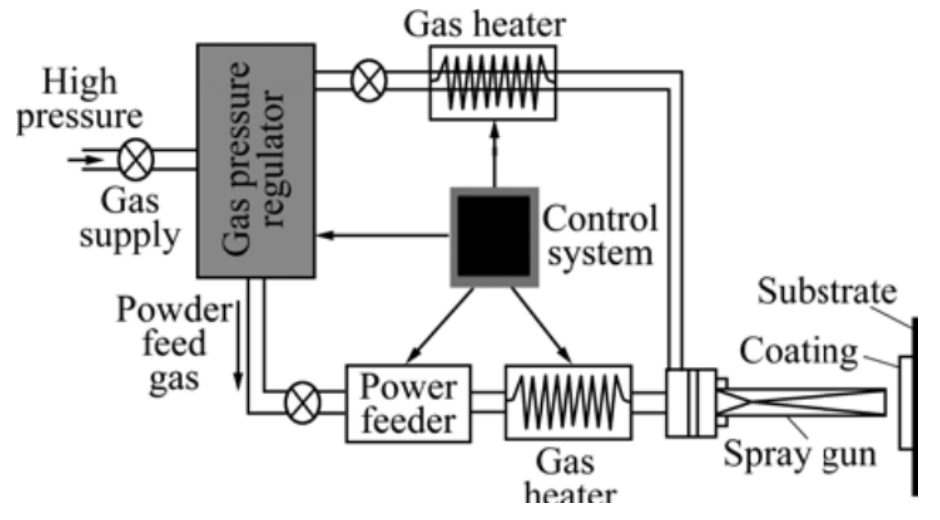

Fig 2 Schematic drawing of CS system

To define the influence on coating by the processing parameters data of cold spraying, coating density is employed to test processing result. Spraying distance, gas temperature and gas pressure are choosen as the main processing parameters. According to the principle of orthogonal design[11], the design of the orthogonal experiments shows in Table 1.

As the coating density and orthogonal Experiments are taken in thought, The result for Orthogonal Experiment is listed in table 2. In Table 2, line $\mathrm{M}_{1}$ explains the average amount of the total four experiments under above all circumtances and $\mathrm{R}$ stands for Xbar-R such as the $\mathrm{R}$ in the first column which goes as follows: $\mathrm{R}=\max \{8.51,8.79,8.40\}-\min \{8.51,8.79,8.40\}=8.79-8.40=0.39$.

According to table 2, when the spraying distance is $30 \mathrm{~mm}$, coating density is biggest. While the gas temperature is $310 \mathrm{C}$, and gas pressure is $2.1 \mathrm{MPa}$, its coating density is biggest . From the $\mathrm{R}_{1}$ on Table 2, it is found that coating density greatly depends on spraying distance, and then gas temperature, and the variation of the gas pressure effects the least.

Tab. 1 Table for orthogonal experiments

\begin{tabular}{cccc}
\hline Experiment no & $\begin{array}{r}\text { Spraying distance } \\
(\mathrm{mm})\end{array}$ & $\begin{array}{r}\text { Gas temperature } \\
(\mathrm{C})\end{array}$ & $\begin{array}{c}\text { Gas pressure } \\
(\mathrm{MPa})\end{array}$ \\
\hline 1 & 20 & 280 & 1.80 \\
2 & 20 & 310 & 2.00 \\
3 & 20 & 340 & 2.20 \\
4 & 30 & 280 & 1.80 \\
5 & 30 & 310 & 2.00 \\
6 & 30 & 340 & 2.20 \\
7 & 40 & 280 & 1.80 \\
8 & 40 & 310 & 2.00 \\
9 & 40 & 340 & 2.20 \\
\hline
\end{tabular}

According to table 2 , $\mathrm{R}$ for spraying distance is 0.39 , which means coating density varies greatly when spraying distance change. Coating is formed on the substrate when the feedstock particles are deformed severely, so the increasement of particle velocity will introduce coating with higher density.

During the spraying process, gas is heated for the purpose of expansion, then gas pressure is increased due to the expansion. Increasement of gas pressure induce the the increasement of particle velocity. As shown in table 2, the optimized gas temperature is $310 \mathrm{C}$ 
Tab.2 The result for orthogonal experiment

\begin{tabular}{ccccc}
\hline Experiment no & $\begin{array}{c}\text { Spraying } \\
\text { distance } \\
(\mathrm{mm})\end{array}$ & $\begin{array}{c}\text { Gas temperature } \\
(\mathrm{C})\end{array}$ & $\begin{array}{c}\text { Gas pressure } \\
(\mathrm{MPa})\end{array}$ & $\begin{array}{c}\text { Coating density } \\
\left(\mathrm{g} / \mathrm{cm}^{3}\right)\end{array}$ \\
\hline 1 & 20 & 280 & 1.80 & 8.47 \\
2 & 20 & 310 & 1.95 & 8.62 \\
3 & 20 & 340 & 2.10 & 8.43 \\
4 & 30 & 280 & 1.80 & 8.82 \\
5 & 30 & 310 & 1.95 & 8.87 \\
6 & 30 & 340 & 2.10 & 8.67 \\
7 & 40 & 280 & 1.80 & 8.54 \\
8 & 40 & 310 & 1.95 & 8.43 \\
9 & 40 & 340 & 2.10 & 8.24 \\
$\mathrm{M}_{1}$ & 8.51 & 8.61 & 8.52 & \\
$\mathrm{M}_{2}$ & 8.79 & 8.64 & 8.56 & \\
$\mathrm{M}_{2}$ & 8.40 & 8.45 & 8.61 & \\
$\mathrm{R}$ & 0.39 & 0.19 & 0.09 & \\
\hline
\end{tabular}

Gas pressure is an important processing parameter for cold spray. And higher particle speed can be reached unless gas pressure exceed critical value. According to the result of orthogonal experiment in table 2, the optimized gas pressure is $2.1 \mathrm{MPa}$.

According to the orthogonal experiment, the optimized parameters for Al cold spray coating on AZ31 magnesium alloy are listed as follows: spraying distance is $30 \mathrm{~mm}$, and gas temperature is 310 $\mathrm{C}$, while gas pressure is $2.1 \mathrm{MPa}$. Fig 3 shows microstructure of coating before and after optimization. It can be seen from Fig 2 that no hole exist on the coating after optimization.
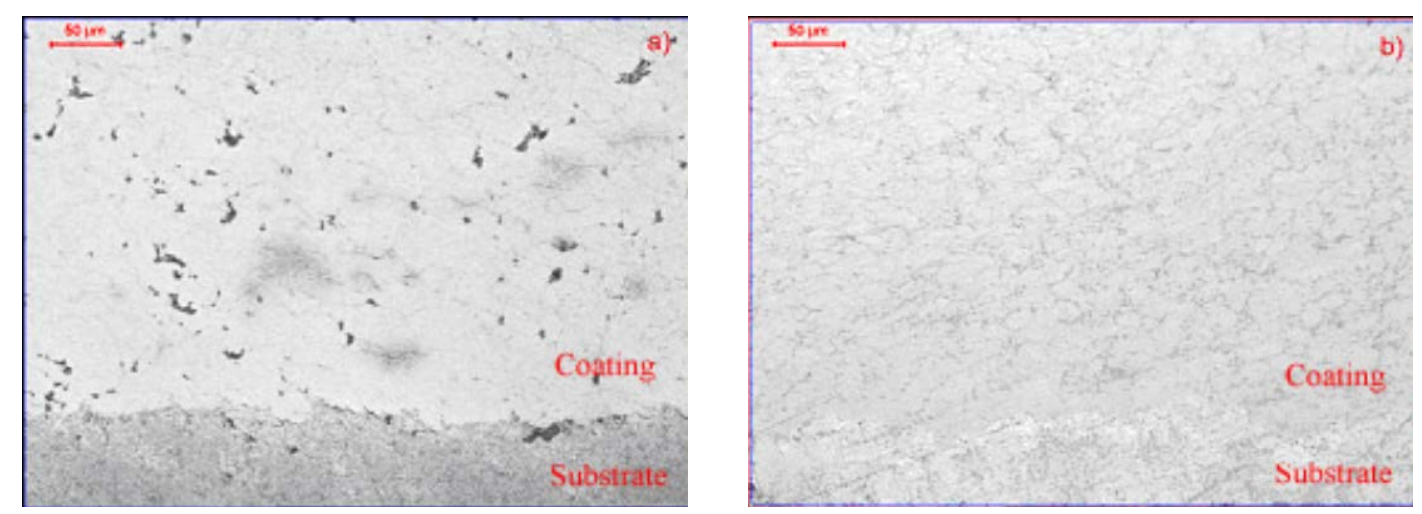

Fig $3 \mathrm{Al}$ coating microstructure (a) before optimization, (b) after optimization

\section{Conclusions}

Optimized Al coating on AZ31 magnesium alloy are sprayed by spraying distance $30 \mathrm{~mm}$ under pressure of 2.1 MPa at $310 \mathrm{C}$. 


\section{Acknowledgments}

Financial support from the National Natural Science Foundation of China (NSFC - Henan Joint Fund of Personnel Training, U1404501) and Doctoral Foundation of Henan University of Science and Technology are acknowledged.

\section{References}

[1] G.L. Song, A. Atrens, Adv. Eng. Mater. 1 (1999) p.11

[2] G.L. Makar, J. Kruger, Int. Mater. Rev. 38 (1993) p.138

[3] F.H. Froes, Mat. Sci. Eng. A Struct. 184 (1994) p.119

[4] H.F. Guo, M.Z. An, Thin Solid Films 500 (2006) p.186

[5] A.R. Shashikala, R. Umarani, S.M. Mayanna, A.K. Sharma, Int. J. Electrochem. Sci. 3 (2008) p.993

[6] J.F. Zhang, C.W. Yan, F.H. Wang, Appl. Surf. Sci. 255 (2009) p.4926

[7] T. Ishizaki, J. Hieda, N. Saito, N. Saito, O. Takai, Electrochim. Acta 55 (2010) p.7094

[8] C Borchers, F Gartner, T Stoltenhoff, H Assadi, H Kreye, J Appl Phys. 93 (2003), p. 10064

[9] RS Lima, J Karthikeyan, CM Kay, J Lindemann, CC Berndt, Thin Solid Films 416 (2002) p. 129

[10] Brasher DG, Butler DJ. Adv Mater Process, 147(1995), p. 37

[11] K T Fang, C X Ma: Orthogonal and Uniform Test Design (Science Press, Beijing 2001) 